\title{
EVALUATION OF 6-NODED QUARETER POINT ELEMENT FOR CRACK ANALYSIS BY ANALYTICAL METHOD
}

\author{
Nanavare Prashant ${ }^{1}$, Vijaykumar N Chalwa ${ }^{2}$, Patil Deogonda ${ }^{3}$ \\ ${ }^{I}$ Assistance Professor, Dept. of Mechanical Engineering, SMSMPITR, Akluj \\ ${ }^{2}$ Dean R\&D, Dept. of Mechanical Engineering, SMSMPITR, Akluj \\ ${ }^{3}$ Assistance Professor, Dept. of Mechanical Engineering, SMSMPITR, Akluj
}

\begin{abstract}
Catastrophic fracture failure of engineering structures is caused by cracks that extend beyond a safe size. Cracks, present to some extent in all structures, either as a result of manufacturing fabrication defects or localized damage in service, may grow by mechanisms such as fatigue, stress-corrosion or creep. The crack growth leads to a decrease in the structural strength. Thus, when the service loading cannot be sustained by the current residual strength, fracture occur leading to the failure of the structure. The analysis of cracks within structures is an important application if the damage tolerance and durability of structures and components are to be predicted. Often cracks cannot be avoided in structures; however the fatigue life of the structure depends on the location and size of these cracks. In order to predict the fatigue life for any component, a fatigue life and crack growth study needs to be performed.
\end{abstract}

\section{INTRODUCTION}

It has been suggested that 50 to 90 percent of all mechanical failures are due to fatigue, and the majority of these failures are unexpected. Fatigue causes failure in many structures in automobiles, ships and aircraft as well as any other device which undergo repeated loading. In 1978, a comprehensive study indicated a cost of $\$ 119$ billion (in 1982 dollars) due to fracture in the United States.

\subsection{Finite Element Analysis}

An analytical solution is a mathematical expression that gives the values of the desired unknown quantity at any location in a body (or structure), and as a consequence, it is valid for an infinite number of locations in the body or structure.

However, analytical solutions can be obtained only for simple engineering problems .It is extremely difficult and many a times impossible, to obtain the exact analytical mathematical solutions for many complex engineering problems. In such cases, the technique known as FINITE ELEMENT METHOD (FEM) is used.

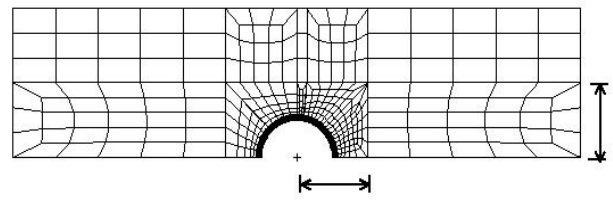

Fig.1 :-(b) Discretization
In FEM the body is divided in to finite number of smaller units known as elements. This process of dividing the body into finite number of elements is known as discretization. Fig.1 illustrates the discretization. The assemblage of elements then represents the original body. These elements are considered interconnected at joints are known as nodes or nodal points. Instead of solving problems for the entire body in one operation, the solutions are formulated for each element and combined to obtain the solution for the original body. This approach is known as going from part to whole. Though it will be theoretically correct to satisfy the continuity requirements all along the edges of elements, this will lead to more complicated analysis.

Hence, in FEM, in order to make analysis more simpler ,it is assumed that the elements are connected at the finite number of joints called NODES or NODAL POINTS. It is only at nodes the continuity equations are required to be satisfied.In FEM, the amount of data to be handled is dependent upon the number of elements in to which the original body is divided.

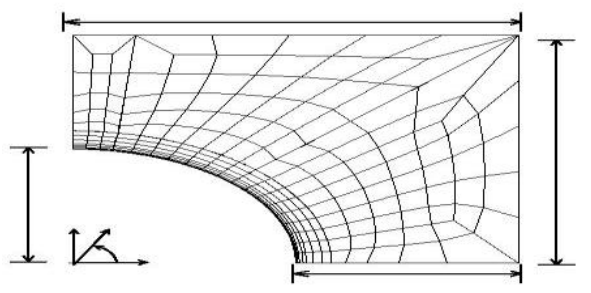

Fig.2: (b) Discretization 
For a large number of elements it is a formidable task to handle the volume of data manually and hence in such cases the use of computers inevitable.

It has been found that the accuracy of solution, in genral, increases with the number of elements taken.However, more number of elements will result in increased computation.

\section{OBJECTIVE AND METHODOLOGY}

The objective of this project is to develop an element the crack tip crack. Project currently focuses on 2D problems.

\section{Problem definition}

Generally crack happens in the problem shown in sketches as shown above

\section{Problem Description}

Crack propagation in a plate with holes at different location is studied.

\section{Problem}

In this problem a simple plate with notch is taken. The plate is considered a plane stress problem. The below figure shows that dimension of the plate

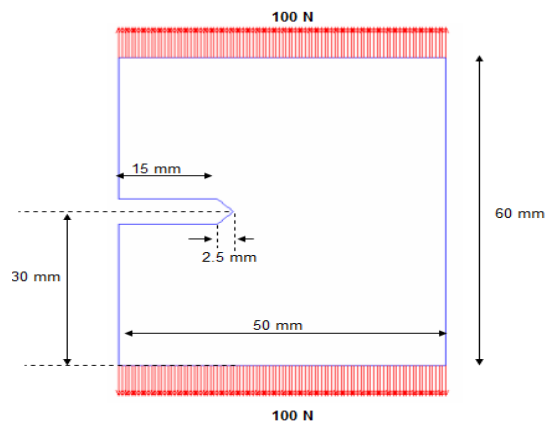

Fig.3.Dimension of the plate

A plate having a notch when a tensile is applied on both side of Plate at the end of notch crack is occurred.

The material; properties used for the plate is given in the table below.

Table 1:- Material properties

\begin{tabular}{|l|l|l|}
\hline Material Properties & Value & Unit \\
\hline $\begin{array}{l}\text { Modulus of Elasticity, } \\
\text { E }\end{array}$ & 210000 & $\mathrm{MPa}$ \\
\hline Poisson ratio, $\mathrm{v}$ & 0.29 & \\
\hline Paris Coefficient, C & $\begin{array}{l}1.33559 \mathrm{e}- \\
13\end{array}$ & $\begin{array}{l}\mathrm{mm} / \mathrm{cycl} \\
\mathrm{e}\end{array}$ \\
\hline Paris Exponent, $\mathrm{n}$ & 2.954 & \\
\hline
\end{tabular}

\section{FORMULATION}

\subsection{Modeling of the Crack}

The main difficulty in modeling the crack in FEM is to model the singularity $(1 /{ } \mathrm{r})$ behavior of the crack tip. Traditionally a very fine mesh was used at the crack tip to capture the singularity behavior. But this makes the computational time expensive. A special type of element is, therefore, used in this formulation. This special type of element is known as quarter point element. An introduction to this kind of element is given below.

\subsection{Quarter Point Elements}

As mentioned earlier, one of the major difficulties in fracture mechanics using FEM is the modeling of the singularity $\left(1 / \mathrm{V}_{\mathrm{r}}\right)$ in the stress field formed at the crack tip. Henshell and Shaw discovered that it was possible to represent the $(1 / \sqrt{ } \mathrm{r})$ stress singularity using quadratic isoperimetric elements. Barsoum formulated a quadratic isoperimetric element able to represent the $(1 / \sqrt{ } \mathrm{r})$ stress singularity moving the mid side node of the two sides to the quarter point position [8]. A brief formulation of the element is given. Figure 5.1 shows the quarter point 8 noded element.

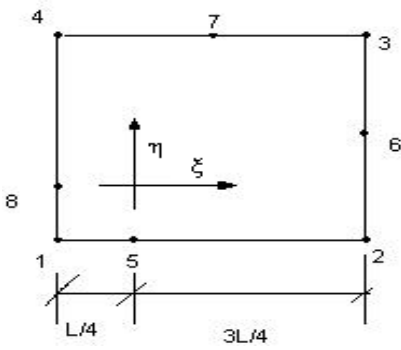

Fig.4:-.Quarter point 8-noded element

The geometry of an 8-noded plane isoparametric element can be mapped into a normalized square space $(\xi, \eta),(-1 \geq \xi \geq 1,-1 \geq$ $\eta \geq 1)$ through the following transformation

$$
\begin{aligned}
& x=\sum_{i=1}^{8} N_{i}(\xi, \eta) x_{i} \\
& y=\sum_{i=1}^{8} N_{i}(\xi, \eta) y_{i}
\end{aligned}
$$

The shape functions for the three nodes can be written as,

$$
\begin{aligned}
& N_{1}=-\frac{1}{2} \xi(1-\xi) \\
& N_{2}=\frac{1}{2} \xi(1+\xi)
\end{aligned}
$$$$
N_{5}=\left(1-\xi^{2}\right) \quad \text { From Equation, }
$$ 
$x=-\frac{1}{2} \xi(1-\xi) x_{1}+\frac{1}{2} \xi(1+\xi) x_{2}+\left(1-\xi^{2}\right) x_{5}$

Choosing, $\mathrm{x} 1=0, \mathrm{x} 2=\mathrm{L}$ and $\mathrm{x} 5=\mathrm{L} / 4$

$x=\frac{1}{2} \xi(1+\xi) L+\left(1-\xi^{2}\right) \frac{L}{4}$

Thus,

$\xi=\left(-1+2 \sqrt{\frac{x}{L}}\right)$

and in the Jacobian, $\frac{\partial x}{\partial \xi}$ is given by:

$\frac{\partial x}{\partial \xi}=\frac{L}{2}(1+\xi)=\sqrt{\frac{x}{L}}$

Which makes the determinant of the Jacobian vanish at the crack tip when $\mathrm{x}=0$

Regarding the displacement along the line 1-5-2:

$u=-\frac{1}{2} \xi(1-\xi) u_{1}+\frac{1}{2} \xi(1+\xi) u_{2}+\left(1-\xi^{2}\right) u_{5}$

And writing in terms of $\mathrm{x}$

$u=-\frac{1}{2}\left(-1+2 \sqrt{\frac{x}{L}}\right)\left[2-2 \sqrt{\frac{x}{L}}\right] u_{1}+\frac{1}{2}\left(-1+2 \sqrt{\frac{x}{L}}\right)\left[2 \sqrt{\frac{x}{L}}\right] u_{2}+\left(4 \sqrt{\frac{x}{L}}-4 \frac{x}{L}\right) u_{5}$

So, the strain in the $\mathrm{x}$ direction is given by:

$$
\begin{aligned}
\varepsilon_{x} & =\frac{d u}{d x}=J^{-1} \frac{d u}{d \xi} \\
& =\frac{d \xi}{d x} \frac{d u}{d \xi} \\
& =-\frac{1}{2}\left[\frac{3}{\sqrt{x L}}-\frac{4}{L}\right] u_{1}+\frac{1}{2}\left[-\frac{1}{\sqrt{x L}}+\frac{4}{L}\right] u_{2}+\left[\frac{2}{\sqrt{x L}}-\frac{4}{L}\right] u_{5}
\end{aligned}
$$

The singularity achieved for the strain filed in Equation 8 is of order $1 / \sqrt{\mathrm{x}}$, therefore, at the crack tip, the stress is infinite which, is the same singularity achieved beyond the elastic plane analysis. A 6-noded triangular element is shown in the Figure 5.

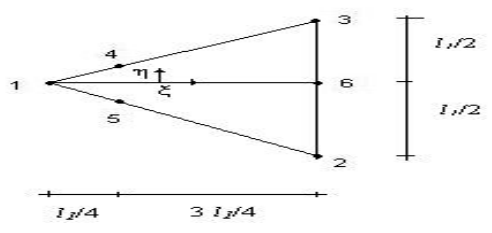

Fig:-5: Quarter point 6-noded element
In this case the singularity is investigated along the $\mathrm{x}$-axis, where $\eta=0$, and for this line we have,

$$
x=-\frac{1}{4}(1+\xi)(1-\xi) l_{1}-\frac{1}{4}(1+\xi)(1-\xi) l_{1}+\frac{1}{2}\left(1-\xi^{2}\right) \frac{l_{1}}{4}+\frac{1}{2}(1+\xi) l_{1}+\frac{1}{2}\left(1-\xi^{2}\right) \frac{l_{1}}{4}
$$

It reduces to, 1

$$
x=\left(\xi^{2}+2 \xi+1\right) \frac{l_{1}}{4}
$$

Thus,

$$
\xi=\left(-1+2 \sqrt{\frac{x}{l_{1}}}\right)
$$

Which is the same singularity achieved in 8-noded element. Quadrilateral quarter point element is used less frequently in practice than the triangular version. These may be because of fewer number of this element being able to place around the crack tip. With fewer elements, the circumferential variations of the stress and displacement fields around a crack tip may be can less accurately represented then the triangular case where more elements can be placed around the tip.

\subsection{Modeling Crack tip using Quarter Point Element}

In the present work, 6-noded quarter point element is used to model the crack tip. The macro developed, clear.mac, has the capability to automatically model the crack tip with 6-noded quarter point element. The user has to input the crack initiation node and the crack tip location. Most of the time, the crack initiates at maximum principles stress. The procedure is shown below in the figures

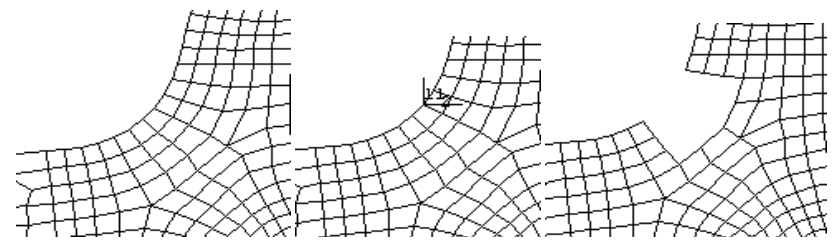

a) Un-cracked region b) Define Crack tip and end point c) Element deletion around crack tip

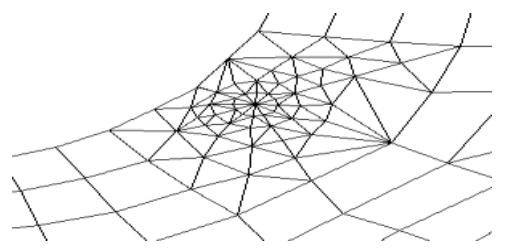

d) Step 4: Local remeshing with QP element

Fig.6:- Automatic Modeling of crack 
Once the crack tip is remeshed with QP element, static analysis is carried out. The stress intensity factor and propagation angle are found out.

\section{CONCLUSIONS AND FUTURE SCOPE}

An element is developed for modeling the crack point. This element widely used by swarts FRANCE 2D, ANSYS

1) Evaluated element valid and used by $\mathrm{s} / \mathrm{w}$

2) Results of $\mathrm{s} / \mathrm{w}$ and modeling are quarter

\section{REFERENCES}

[1]. Maitra G. M., Handbook of Gear Design, Tata McGrawHill Publishing Company, 1988

[2]. Sharma P. C. Aggarwal, D. K., Machine Design, S. K. Kataria \& Sons, 2001

[3]. Lewicki D. G., Ballarini R., "Effect of rim thickness on gear crack propagation path", Journal of Mechanical Design, Vol.119, No.1, 1998, pp. 226-230

[4]. Lewicki D. G., Spievak L.E., Wawrzynek P. A.," Consideration Of Moving Tooth load in gear crack propagation prediction", Proceeding of the 8th International Power Transmission and Gearing Conference, Baltimore, MD, Sep. 2000

[5]. Lewicki D. G., "Effect of speed (centrifugal load) on gear crack propagation direction".

[6]. Golde S., Jelaska D., Kramberger J.,"A computational model for Calculation of load capacity of gears" International Journal of Fatigue, Vol.24, No. 10, 2002, pp. 1013-1020

[7]. Guagliano M., Vergani L.,"Effect of crack closure on gear crack Propagation", International Journal of Fatigue, Vol. 23, 2001, pp. 65-73

[8]. Cavalcanti Marcus, Luciano M., Partridge P., "A comparative Analysis between three different approaches on obtaining stress Intensity factor", Computational Mechanics: New trends and Applications, Barcelona, Spain, 1998.

[9]. Ciavarella M., Demelio G., "Numerical methods for the Optimization of specific sliding, stress concentration and fatigue Life gears", International Journal of Fatigue, Vol. 21, 1999, pp. 465-474

[10]. Pahan S., Hellen T., Flasker J., Glodez S., “ Numerical methods For determining stress intensity factors vs. crack depth in gear Tooth roots", International Journal of Fatigue, Vol. 19, No. 10, 1997, pp. 673-685

[11]. MackAlender M., "Tooth Interior Fatigue Fracture \& Robustness of Gears", PhD Thesis, 2001, Royal Institute of Technology, Sweden. 